\title{
Remarkably enhanced dielectric stability and energy storage properties in BNT-BST relaxor ceramics by A-site defect engineering for pulsed power applications
}

\author{
Zhipeng $\mathrm{LI}^{a, \dagger}$, Dong-Xu LI ${ }^{a, b, \dagger}$, Zong-Yang SHEN ${ }^{a, *}$, Xiaojun ZENG ${ }^{a}$, Fusheng SONG ${ }^{a}$, \\ Wenqin $\mathrm{LUO}^{a}$, Xingcai $\mathrm{WANG}^{c}$, Zhumei $\mathrm{WANG}^{a}$, Yueming $\mathrm{LI}^{a}$ \\ ${ }^{a}$ Energy Storage and Conversion Ceramic Materials Engineering Laboratory of Jiangxi Province, \\ China National Light Industry Key Laboratory of Functional Ceramic Materials, School of \\ Materials Science and Engineering, Jingdezhen Ceramic University, Jingdezhen 333403, China \\ ${ }^{b}$ State Key Laboratory of Advanced Technology for Materials Synthesis and Processing, School of \\ Materials Science and Engineering, Wuhan University of Technology, Wuhan 430070, China \\ ${ }^{c}$ Chengdu Hongke Electronic Technology Co., Ltd., Chengdu 610000, China
}

Received: June 26, 2021; Revised: August 20, 2021; Accepted: August 31, 2021

(C) The Author(s) 2021.

\begin{abstract}
Lead-free bulk ceramics for advanced pulsed power capacitors show relatively low recoverable energy storage density $\left(W_{\text {rec }}\right)$ especially at low electric field condition. To address this challenge, we propose an A-site defect engineering to optimize the electric polarization behavior by disrupting the orderly arrangement of $\mathrm{A}$-site ions, in which $\mathrm{Ba}_{0.105} \mathrm{Na}_{0.325} \mathrm{Sr}_{0.245-1.5 x} \square_{0.5 x} \mathrm{Bi}_{0.325+x} \mathrm{TiO}_{3}$ (BNS $_{0.245-1.5 x} \square_{0.5 x} \mathrm{~B}_{0.325+x} \mathrm{~T}, x=0,0.02,0.04,0.06$, and 0.08 ) lead-free ceramics are selected as the representative. The $\mathrm{BNS}_{0.245-1.5 x} \square_{0.5 x} \mathrm{~B}_{0.325+x} \mathrm{~T}$ ceramics are prepared by using pressureless solid-state sintering and achieve large $W_{\text {rec }}\left(1.8 \mathrm{~J} / \mathrm{cm}^{3}\right)$ at a low electric field $(@ 110 \mathrm{kV} / \mathrm{cm})$ when $x=0.06$. The value of $1.8 \mathrm{~J} / \mathrm{cm}^{3}$ is super high as compared to all other $W_{\text {rec }}$ in lead-free bulk ceramics under a relatively low electric field $(<160 \mathrm{kV} / \mathrm{cm})$. Furthermore, a high dielectric constant of 2930 within $15 \%$ fluctuation in a wide temperature range of $40-350{ }^{\circ} \mathrm{C}$ is also obtained in $\mathrm{BNS}_{0.245-1.5 x} \square_{0.5 x} \mathrm{~B}_{0.325+x} \mathrm{~T}$ $(x=0.06)$ ceramics. The excellent performances can be attributed to the A-site defect engineering, which can reduce remnant polarization $\left(P_{\mathrm{r}}\right)$ and improve the thermal evolution of polar nanoregions (PNRs). This work confirms that the $\mathrm{BNS}_{0.245-1.5 x} \square_{0.5 x} \mathrm{~B}_{0.325+x} \mathrm{~T}(x=0.06)$ ceramics are desirable for advanced pulsed power capacitors, and will push the development of a series of $\mathrm{Bi}_{0.5} \mathrm{Na}_{0.5} \mathrm{TiO}_{3}$ (BNT)-based ceramics with high $W_{\text {rec }}$ and high-temperature stability.

Keywords: relaxor ferroelectrics; energy storage ceramics; ceramic capacitor; $\mathrm{Bi}_{0.5} \mathrm{Na}_{0.5} \mathrm{TiO}_{3}$ (BNT); defect engineering
\end{abstract}

\footnotetext{
$\dagger$ Zhipeng Li and Dong-Xu Li contributed equally to this work.

* Corresponding author.

E-mail: shenzongyang@163.com
} 


\section{Introduction}

Dielectric capacitor is an indispensable component in contemporary electronic devices, which fulfills different functions such as direct current blocking, coupling, filtering, and pulse discharge [1-3]. Considering the complicated working environment, especially high temperatures $\left(150-200{ }^{\circ} \mathrm{C}\right.$, even up to $\left.300{ }^{\circ} \mathrm{C}\right)$, ceramic dielectrics would be more suitable for energy storage candidates than other polymer materials [4]. Generally, the energy storage properties of ceramic dielectrics can be evaluated by the following equations [5]:

$$
\begin{gathered}
W=\int_{0}^{P_{\max }} E \mathrm{~d} P \\
W_{\text {rec }}=\int_{P_{\mathrm{r}}}^{P_{\max }} E \mathrm{~d} P \\
\eta=\frac{W_{\text {rec }}}{W} \times 100 \%
\end{gathered}
$$

where $W, W_{\text {rec }}, \eta, E, \mathrm{~d} P, P_{\max }$, and $P_{\mathrm{r}}$ denote total energy storage density, recoverable energy storage density, energy efficiency, applied external electric field, polarization increment at $E$, maximum polarization, and remnant polarization, respectively. Therefore, high $P_{\text {max }}$, low $P_{\mathrm{r}}$, and high breakdown strength $E_{\mathrm{b}}$ are important factors to achieve high $W_{\text {rec }}[6,7]$. However, high applied electric field may limit its application in integrated electronic circuits, as well as in wearable or implantable devices requiring low electric field. Pb-based relaxor ferroelectric and antiferroelectric ceramics had been considered as potential candidates, while the toxicity of $\mathrm{Pb}$ limits its application [8,9]. It is urgent to design and develop new $\mathrm{Pb}$-free systems with high $W_{\text {rec }}$ especially under relatively low electric field.

Bismuth sodium titanate $\left(\mathrm{Bi}_{0.5} \mathrm{Na}_{0.5} \mathrm{TiO}_{3}, \quad\right.$ BNT) possesses characteristics of complicated phase structure with high $P_{\max }$, and hence is considered as a promising energy storage ferroelectric material [9-13]. Noted that a high $P_{\mathrm{r}}$ and poor sintering behavior of pure BNT ceramic result in a low $W_{\text {rec}}$. Different methods, therefore, are utilized to improve $W_{\text {rec }}$ such as chemical doping, glass modification, multilayer structure design, and advanced sintering technology [14-22]. For chemical doping, it can be divided into chemical equivalent and aliovalent doping. Especially, the chemical aliovalent doping includes "donor" and "acceptor" doping, which can induce different types of defects and improve the properties of materials. For example, Cao et al. [23] used $\mathrm{Mn}^{2+}$ as acceptor dopant to substitute $\mathrm{B}$-site ions of $0.7[0.94 \mathrm{NBT}-0.06 \mathrm{BT}]-0.3 \mathrm{ST}$ ceramic, and acquired a high $W_{\text {rec }}$ of $1.06 \mathrm{~J} / \mathrm{cm}^{3}$. Xu et al. [24] found a pinched $P-E$ loop behavior in Ta donor doped BNT-0.06BT ferroelectric ceramic. It can be observed that defect engineering can effectively improve energy storage properties by forming different types of defect dipoles. For vacancy defect, on the one hand, it can influence internal electric field to reduce $P_{\mathrm{r}}$, and on the other hand, it may pin domain wall to inhibit its switching. However, a few reports pointed out the chemical defects by adjusting the element ratio in composition to optimize the energy storage properties of BNT-based ceramics.

Based on our previous work, a binary solid solution of $\left(\mathrm{Bi}_{0.5} \mathrm{Na}_{0.5}\right)_{0.65}\left(\mathrm{Ba}_{0.3} \mathrm{Sr}_{0.7}\right)_{0.35} \mathrm{TiO}_{3} \quad$ (BNT-BST) is considered as a good energy storage material due to "clamped" behavior in $P-E$ loop and high dielectric constant $\varepsilon_{\mathrm{r}}(\sim 4000)$ at room temperature $[25,26]$. However, its relatively high $P_{\mathrm{r}}$ and poor dielectric temperature stability make it hard to obtain high $W_{\text {rec }}$. Based on the above considerations, we propose an A-site defect engineering, i.e., adjusting the $\mathrm{Bi} / \mathrm{Sr}$ ratio by generating different concentrations of $\mathrm{Sr}^{2+}$ vacancy to enhance $W_{\text {rec }}$ in this work. Consequently, the phase structure, micrograph, dielectric temperature stability, and energy storage properties of $\mathrm{Ba}_{0.105} \mathrm{Na}_{0.325} \mathrm{Sr}_{0.245-1.5 x} \square_{0.5 x} \mathrm{Bi}_{0.325+x} \mathrm{TiO}_{3}$ ceramics are investigated.

\section{Experimental}

$\mathrm{Ba}_{0.105} \mathrm{Na}_{0.325} \mathrm{Sr}_{0.245-1.5 x} \square_{0.5 x} \mathrm{Bi}_{0.325+x} \mathrm{TiO}_{3}\left(\mathrm{BNS}_{0.245-1.5 x} \square_{0.5 x}\right.$ $\mathrm{B}_{0.325+x} \mathrm{~T}, x=0,0.02,0.04,0.06$, and 0.08 ) ceramics were fabricated using a solid-state process. Raw materials $\mathrm{Bi}_{2} \mathrm{O}_{3}(99.9 \%), \mathrm{Na}_{2} \mathrm{CO}_{3}(99.8 \%), \mathrm{TiO}_{2}(99.9 \%)$, $\mathrm{BaCO}_{3}\left(99.0 \%\right.$ ), and $\mathrm{SrCO}_{3}(99.9 \%)$ (purchased from Sinopharm Chemical Reagent Co., Ltd., Shanghai, China) were weighted according to stoichiometric formula and mixed in planetary ball mill for $24 \mathrm{~h}$ with zirconia balls in ethanol. After separating the balls, the mixtures were dried, calcined at $800{ }^{\circ} \mathrm{C}$ for $3 \mathrm{~h}$, and then milled again for $24 \mathrm{~h}$. The powder was compacted into pellets of $13 \mathrm{~mm}$ in diameter and about $1 \mathrm{~mm}$ in thickness under the pressure of $120 \pm 10 \mathrm{MPa}$ after granulated by adding polyvinyl alcohol solution (PVA, $5 \mathrm{wt} \%$ ). The disks were preheated at $650{ }^{\circ} \mathrm{C}$ for $2 \mathrm{~h}$ to remove PVA binder, and finally sintered at $1180-1240{ }^{\circ} \mathrm{C}$ for $2 \mathrm{~h}$ in air followed by furnace cooling. 
The phase structure evolution was identified using the X-ray diffraction (XRD, D8-Advance, Bruker, Germany) with $\mathrm{Cu} \mathrm{K} \alpha$ radiation and the Raman spectroscope (in Via, Renishaw, UK). The microstructure features of the ceramic sample were observed by a scanning electron microscope (SEM, JSM-6700F, JEOL, Japan) after polishing and thermally etching. For electrical performance testing, ceramic samples were polished to smooth and parallel in both surfaces and then painted Ag electrode on both sides. The dielectric properties of ceramics were measured using a precision impedance analyzer (HP4294A, Agilent, USA) over a temperature range from -100 to $400{ }^{\circ} \mathrm{C}$. For $P-E$ loop and charge-discharge measurements, the ceramic samples were polished to $0.3-0.35 \mathrm{~mm}$ and covered a central electrode with margin blank on both sides. The $P-E$ hysteresis loops and $I-E$ curves were examined using a ferroelectric analyzer at $10 \mathrm{~Hz}$ (Trek model 609B, USA) based on a standard sawyer-tower circuit. The temperature dependent charge-discharge capability was tested using a designed RLC circuit (CFD-003, Tongguo Technology, Shanghai, China) being connected to a temperature controlled chamber.

\section{Results and discussion}

Figure 1(a) shows XRD patterns of $\mathrm{BNS}_{0.245-1.5 x} \square_{0.5 x} \mathrm{~B}_{0.325+x} \mathrm{~T}$ ceramics at $2 \theta=20^{\circ}-80^{\circ}$. All samples are pure pseudocubic perovskite structure without trace of any other secondary phases. As seen from Fig. 1(b), the diffraction peak (200) slightly shifts toward a high angle with the increase of $x$ value, indicating that the cell volume gradually decreases. This phenomenon

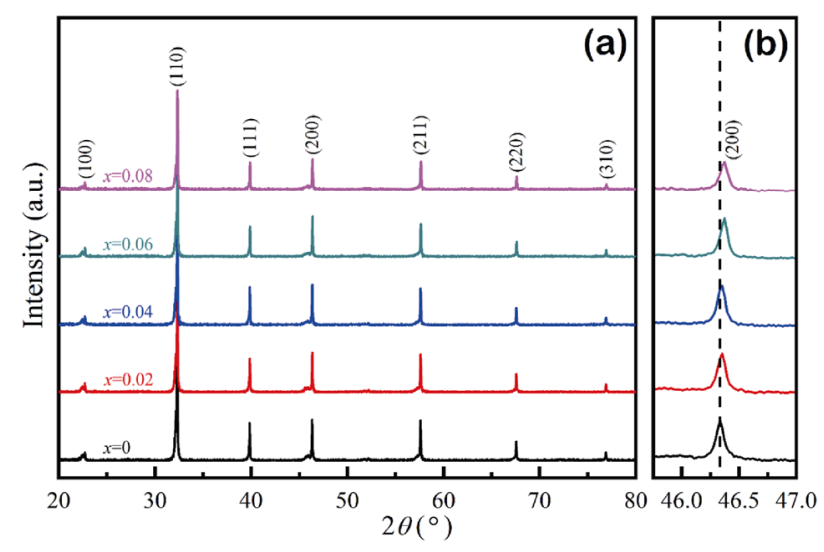

Fig. 1 XRD patterns of $\mathrm{BNS}_{0.245-1.5 x} \square_{0.5 x} \mathrm{~B}_{0.325+x} \mathrm{~T}$ ceramics: (a) $2 \theta=20^{\circ}-80^{\circ}$ and (b) $2 \theta=46^{\circ}-47^{\circ}$. should be attributed to the following reasons: One is the replacement of $\mathrm{Bi}^{3+}$ ions with a smaller ionic radius $\left(r_{\mathrm{i}}=1.35 \AA\right.$, coordination number $\left.=12\right)$ to $\operatorname{Sr}^{2+}\left(r_{\mathrm{i}}=\right.$ $1.44 \AA, \mathrm{CN}=12$ ) with a larger one; and the other is that $\mathrm{Sr}$ vacancy content gradually increases with $x$ value, while the existence of vacancy provides a space for lattice contraction.

It is well known that the Raman spectroscope is an effective tool to investigate the crystalline structure information and phase transition. Figure 2(a) shows Raman spectra of $\mathrm{BNS}_{0.245-1.5 x} \square_{0.5 x} \mathrm{~B}_{0.325+x} \mathrm{~T}$ ceramics at room temperature. Generally, BNT material possesses 16 active phonon modes, and the irreducible representation is $\Gamma_{\text {Raman }}=4 \mathrm{~A}_{1}+1 \mathrm{~B}_{1}+3 \mathrm{~B}_{2}+8 \mathrm{E}$ based on the group theory [27,28]. Figure 2(b) displays the fitted Raman pattern only including eight modes for pure BNT-BST ceramics at room temperature, which should be attributed to disorder occupation of ions at A-site and polycrystalline feature of ceramics. In order to better illustrate the results, four main regions can be classified into the Raman spectra: (1) The modes below $200 \mathrm{~cm}^{-1}(v 1, v 2)$ are related to A-site cation vibration, including $\mathrm{Bi}^{3+}, \mathrm{Na}^{+}, \mathrm{Ba}^{2+}$, and $\mathrm{Sr}^{2+}$ ions; (2) the modes around $200-400 \mathrm{~cm}^{-1}(v 3, v 4)$ should be associated with the vibration of $\mathrm{Ti}-\mathrm{O}$ bond; (3) the modes from 400 to $700 \mathrm{~cm}^{-1}(v 5, v 6)$ are related to $\left[\mathrm{TiO}_{6}\right.$ ] vibrations, namely the breathing and stretching of the oxygen octahedron; (4) the modes above $700 \mathrm{~cm}^{-1}(v 7, v 8)$ are ascribed to the super-position of vibration $\mathrm{A}_{1}$ (longitudinal optical) and $\mathrm{E}$ (longitudinal optical) overlapping bands [28-31]. The Raman patterns are decomposed by Lorentz peak fitting to investigate the effect of $x$ value on the vibration modes. The fitted Raman patterns for the represented $\mathrm{BNS}_{0.245-1.5 x} \square 0.5 x \mathrm{~B}_{0.325+x} \mathrm{~T}$ ceramics with $x=0$ and $x=0.06$ are shown in Figs. 2(b) and 2(c), respectively. With the increase of $x$ value, the $v 2$ phonon mode's wavenumber presents an obvious shifting upward tendency, and signal intensity enhances as shown in Fig. 2(d). Meanwhile, the $v 3$ phonon mode's wavenumber also shows a similar tendency. The results may be ascribed to the enhancement of the polarity of unit cell by the increase of Sr vacancy $[32,33]$. Furthermore, it can be seen that the gap of wavenumber between $v 5$ and $v 6$ gradually increases, and the intensity of the $v 6$ phonon mode has a slight enhancement, which should be related to the strengthening of the $\mathrm{TiO}_{6}$ octahedral distortion, as shown in Fig. 2(d).

Figure 3 displays the micrograph feature of polished and thermally-etched $\mathrm{BNS}_{0.245-1.5 x} \square_{0.5 x} \mathrm{~B}_{0.325+x} \mathrm{~T}$ ceramics. 
It can be seen from Figs. 3(a)-3(e) that $\mathrm{BNS}_{0.245-1.5 x} \square_{0.5 x} \mathrm{~B}_{0.325+x} \mathrm{~T}$ ceramics possess uniform grains and extremely high density. As $x$ value increases, the grain size gradually increases (Fig. 3(f)), which should be attributed to the following two reasons: One is that $\mathrm{Bi}^{3+}$ replaces the A-site ion, and the lattice shrinkage will cause stress; and the other is that $\mathrm{Bi}^{3+}$ replaces $\mathrm{Sr}^{2+}$,
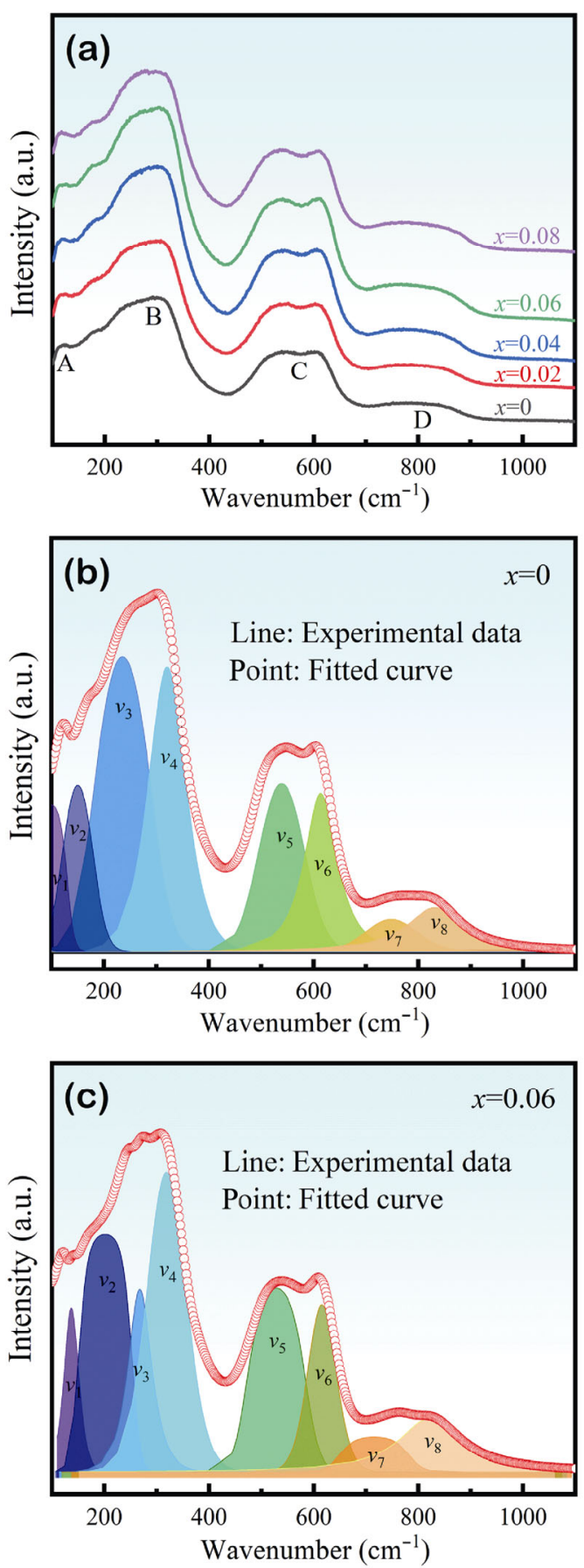

in order to maintain charge balance, defects such as $\mathrm{Sr}$ vacancy and empty lattices will be formed, and stress will also be generated, which accelerates the mass transfer rate between particles and weakens the competition with the adjacent grains, leading to accelerated grain growth and densification promotion of ceramics during the sintering process [34].
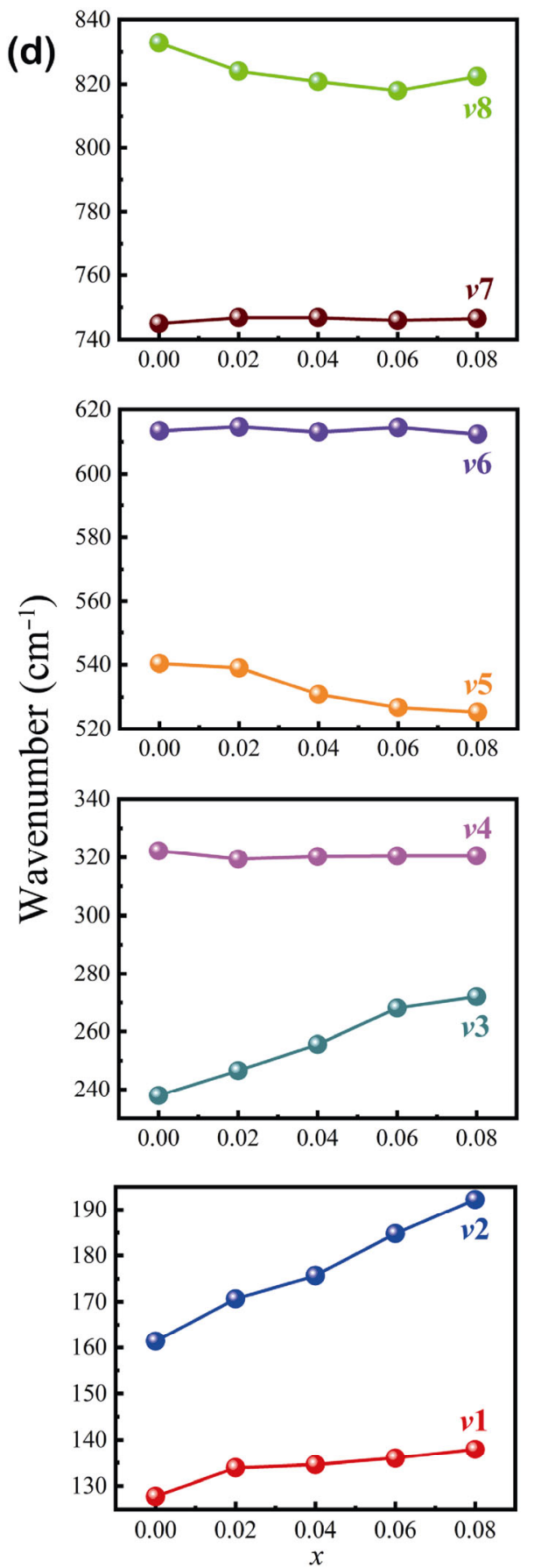

Fig. 2 (a) Raman patterns of $\mathrm{BNS}_{0.245-1.5 x} \square_{0.5 x} \mathrm{~B}_{0.325+x} \mathrm{~T}$ ceramics at room temperature. Lorentz peak fitting of Raman pattern for represented $\mathrm{BNS}_{0.245-1.5 x} \square_{0.5 x} \mathrm{~B}_{0.325+x} \mathrm{~T}$ ceramics with (b) $x=0$ and (c) $x=0.06$. (d) Wavenumbers of Raman peaks from $v 1$ to $v 8$ of $\mathrm{BNS}_{0.245-1.5 x} \square_{0.5 x} \mathrm{~B}_{0.325+x} \mathrm{~T}$ ceramics as a function of $x$ value. 

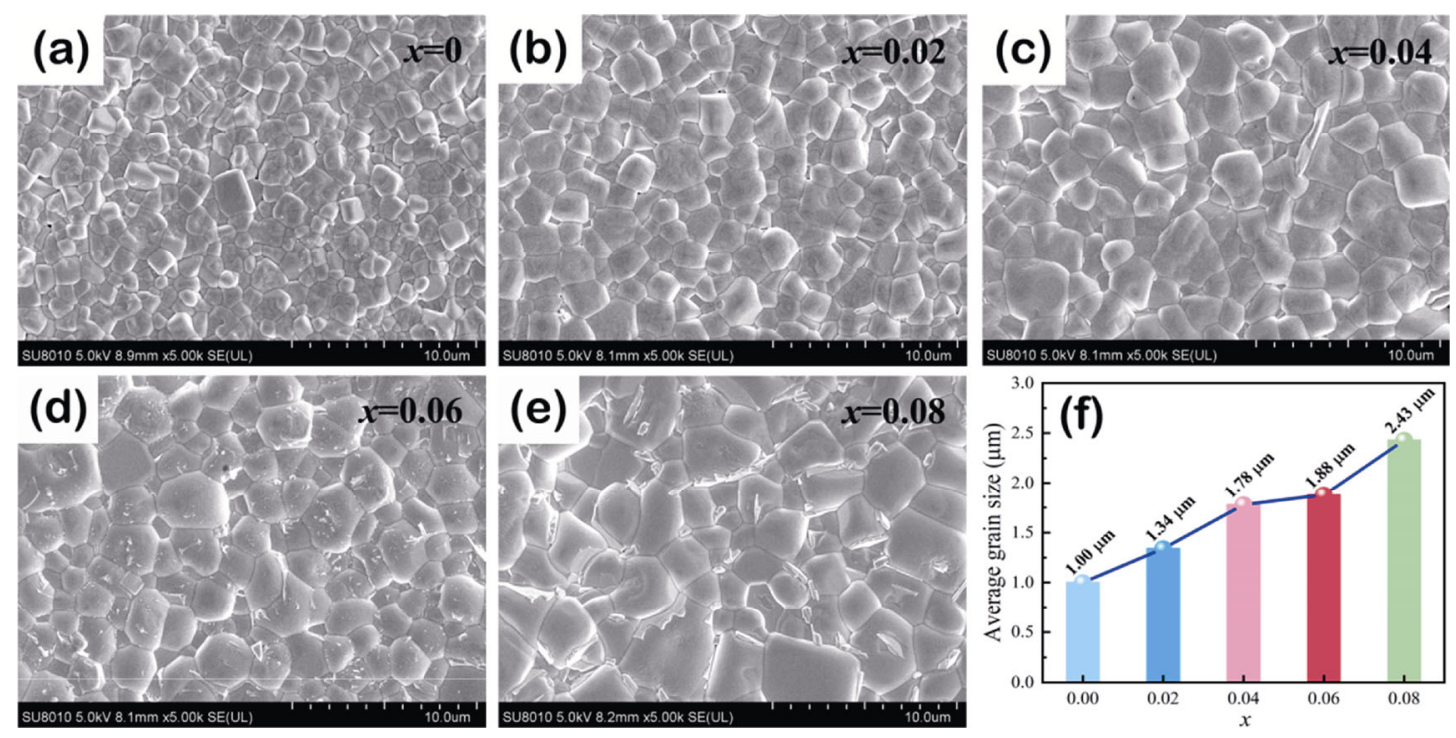

Fig. 3 SEM images of polished and thermally-etched surface of $\mathrm{BNS}_{0.245-1.5 x} \square_{0.5 x} \mathrm{~B}_{0.325+x} \mathrm{~T}$ ceramics: (a) $x=0$, (b) $x=0.02$, (c) $x=0.04$, (d) $x=0.06$, and (e) $x=0.08$; and (f) average grain size of $\mathrm{BNS}_{0.245-1.5 x} \square_{0.5 x} \mathrm{~B}_{0.325+x} \mathrm{~T}$ ceramics as a function of $x$ value.

Figures 4(a)-4(e) show temperature dependence of dielectric properties for $\mathrm{BNS}_{0.245-1.5 x} \square_{0.5 x} \mathrm{~B}_{0.325+x} \mathrm{~T}$ ceramics with different $x$ values at frequencies of $1 \mathrm{kHz}$, $10 \mathrm{kHz}, 100 \mathrm{kHz}$, and $1 \mathrm{MHz}$. It should be mentioned that relaxor ferroelectric has two obvious characteristics: One is that $T_{\mathrm{m}}$, the absolute temperature corresponding to the maximum dielectric constant $\varepsilon_{\mathrm{m}}$, shifts toward high temperature with increasing frequency, and the other one is that dielectric constant at $T_{\mathrm{m}}$ decreases with the increase of frequency whereas that of loss tangent follows the reverse order. Meanwhile, a modified Curie-Weiss law is applied to evaluate the relaxor characteristic [35]:

$$
\frac{1}{\varepsilon_{\mathrm{r}}}-\frac{1}{\varepsilon_{\mathrm{m}}}=\frac{\left(T-T_{\mathrm{m}}\right)^{\gamma}}{C}
$$

where $\varepsilon_{\mathrm{r}}$ and $C$ are the relative dielectric constant $T$ is the measured actual temperature and the Curie constant, respectively. The diffuseness factor $\gamma$ decreases with decreasing relaxor degree and varies between 1 (for normal ferroelectric) and 2 (for ideal relaxor ferroelectric) [36]. With increasing $x$ value, $\gamma$ value increases from 1.71 to 2.00 , indicating that relaxor characteristic is effectively enhanced. For pure BNT-BST ceramics, one dielectric peak at $T_{\mathrm{m}}$ and obvious relaxor behavior below $T_{\mathrm{m}}$ can be observed. After composition modification, wave-like double peaks can be found in dielectric spectra, and corresponding temperatures are named as $T_{\mathrm{m} 1}$ and $T_{\mathrm{m} 2}$. Noted that dielectric relaxor behavior only exists at a temperature below $T_{\mathrm{m} 1}$, and thus dielectric peak at $T_{\mathrm{m} 1}$ is similar to that at $T_{\mathrm{m}}$. Thus, a new dielectric peak at $T_{\mathrm{m} 2}$ should be induced by the $\mathrm{Bi}-\mathrm{Sr}$ ratio change. In addition, it can be seen that $T_{\mathrm{m} 1}$ and $T_{\mathrm{m} 2}$ correspond to the transition from relaxor to ferroelectric phase and ferroelectric to paraelectric phase, respectively. Actually, a similar phenomenon can also be observed in other BNT-based systems while the related reason is still controversial [32,37-40].

Temperature coefficient of capacitance (TCC) is a crucial factor to influence its application scenes. In general, it can be calculated by Eq. (5):

$$
\mathrm{TCC}=\frac{\varepsilon-\varepsilon_{\text {base }}}{\varepsilon_{\text {base }}}
$$

where $\varepsilon_{\text {base }}$ denotes dielectric constant at a based temperature. As $x$ value increases, the dielectric peak at $T_{\mathrm{m} 1}$ is suppressed, while the temperature difference $\Delta T=T_{\mathrm{m} 2}-T_{\mathrm{m} 1}$ is gradually enhanced, which is beneficial for enhancing temperature stability. Figure 4(f) shows TCC of $\mathrm{BNS}_{0.245-1.5 x} \square_{0.5 x} \mathrm{~B}_{0.325+x} \mathrm{~T}$ ceramics with different $x$ values by choosing $150{ }^{\circ} \mathrm{C}$ as the based temperature. With increasing $x$ value, dielectric temperature stability is effectively enhanced especially at high temperatures, which is attributed to the appearance of a new dielectric peak at $T_{\mathrm{m} 2}$. For $x=0.06$ composition, a wide temperature range of TCC $\leqslant \pm 15 \%$ at the temperature range of $40-350{ }^{\circ} \mathrm{C}$.

In order to further explore the reason for generating dielectric peak at $T_{\mathrm{m} 2}$, a variable Raman spectrum is used. Figure 5 shows Raman spectra and wavenumber 

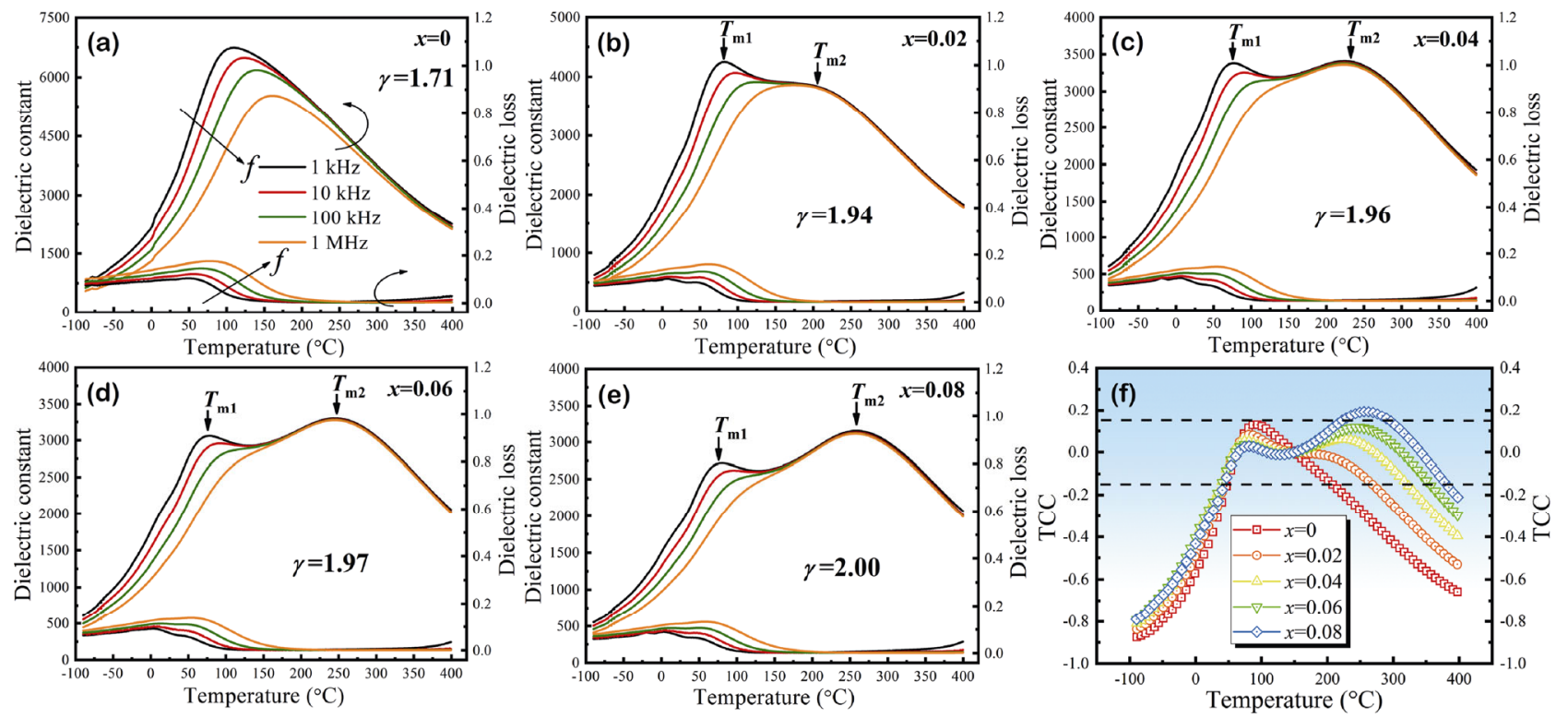

Fig. 4 Temperature dependent dielectric constants and loss of $\mathrm{BNS}_{0.245-1.5 x} \square_{0.5 x} \mathrm{~B}_{0.325+x} \mathrm{~T}$ ceramics at typical frequencies: (a) $x=$ 0 , (b) $x=0.02$, (c) $x=0.04$, (d) $x=0.06$, and (e) $x=0.08$; and (f) TCC for $\mathrm{BNS}_{0.245-1.5 x} \square_{0.5 x} \mathrm{~B}_{0.325+x} \mathrm{~T}$ ceramics with different $x$ values by choosing $150{ }^{\circ} \mathrm{C}$ as the based temperature.

of Raman peaks of $\mathrm{BNS}_{0.245-1.5 x} \square_{0.5 x} \mathrm{~B}_{0.325+x} \mathrm{~T}$ ceramics with $x=0.06$ over a temperature range from room temperature to $275{ }^{\circ} \mathrm{C}$. As temperature increases, the signals of modes $v 2$ and $v 6$ gradually present a disappeared tendency, while other modes change slightly, as shown in Fig. 5(a). All modes display a decreased tendency, with no abrupt change in wavenumber (Fig. 5(b)). The result illustrates that modes $v 2$ and $v 6$ are sensitive to phase structure of $\mathrm{BNS}_{0.245-1.5 x} \square_{0.5 x} \mathrm{~B}_{0.325+x} \mathrm{~T}$ ceramics with $x=0.06$. The slow transitions of modes $v 2$ and $v 6$ both demonstrate that phase structure of $x=0.06$ composition has a slight change. Therefore, it can be concluded that the new dielectric peak at $T_{\mathrm{m} 2}$ should be attributed to the thermal evolution of polar nanoregions (PNRs) affected by the concentration of Sr vacancy [40]. Furthermore, it should be noted that $T_{\mathrm{m} 2}$ has a slowly increased tendency as $x$ increases, and this may due to the decrease of structural stability by increasing $\mathrm{Sr}$ vacancy. And then higher temperature is needed to adjust the structural stability because $T_{\mathrm{m} 2}$ corresponds to ferroelectric-paraelectric phase transition temperature.

Figure 6(a) shows $P-E$ loops of $\mathrm{BNS}_{0.245-1.5 x} \square_{0.5 x} \mathrm{~B}_{0.325+x} \mathrm{~T}$ ceramics at $60 \mathrm{kV} / \mathrm{cm}$ and room temperature. As $x$
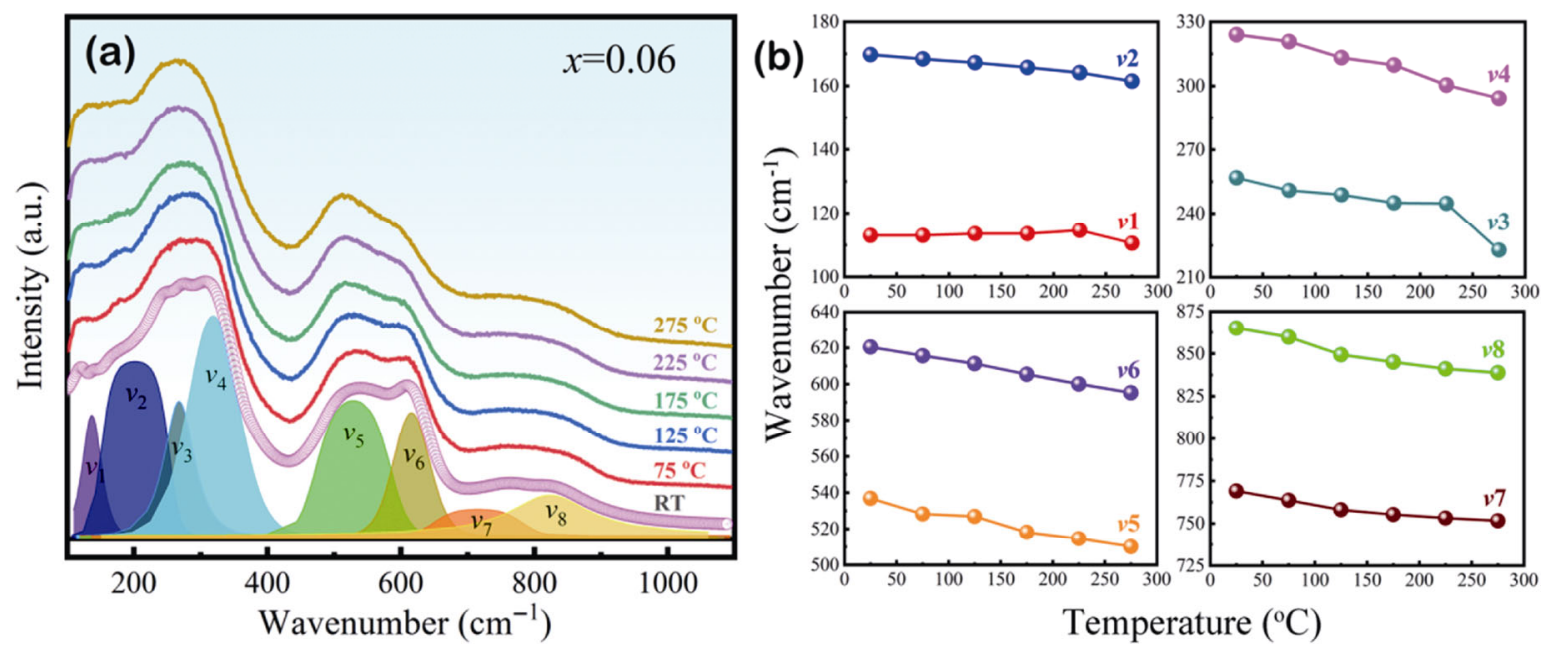

Fig. 5 (a) Raman spectra and (b) wavenumbers of Raman peaks from $v 1$ to $v 8$ of $\mathrm{BNS}_{0.245-1.5 x} \square_{0.5 x} \mathrm{~B}_{0.325+x} \mathrm{~T}$ ceramics with $x=$ 0.06 at different temperatures. 

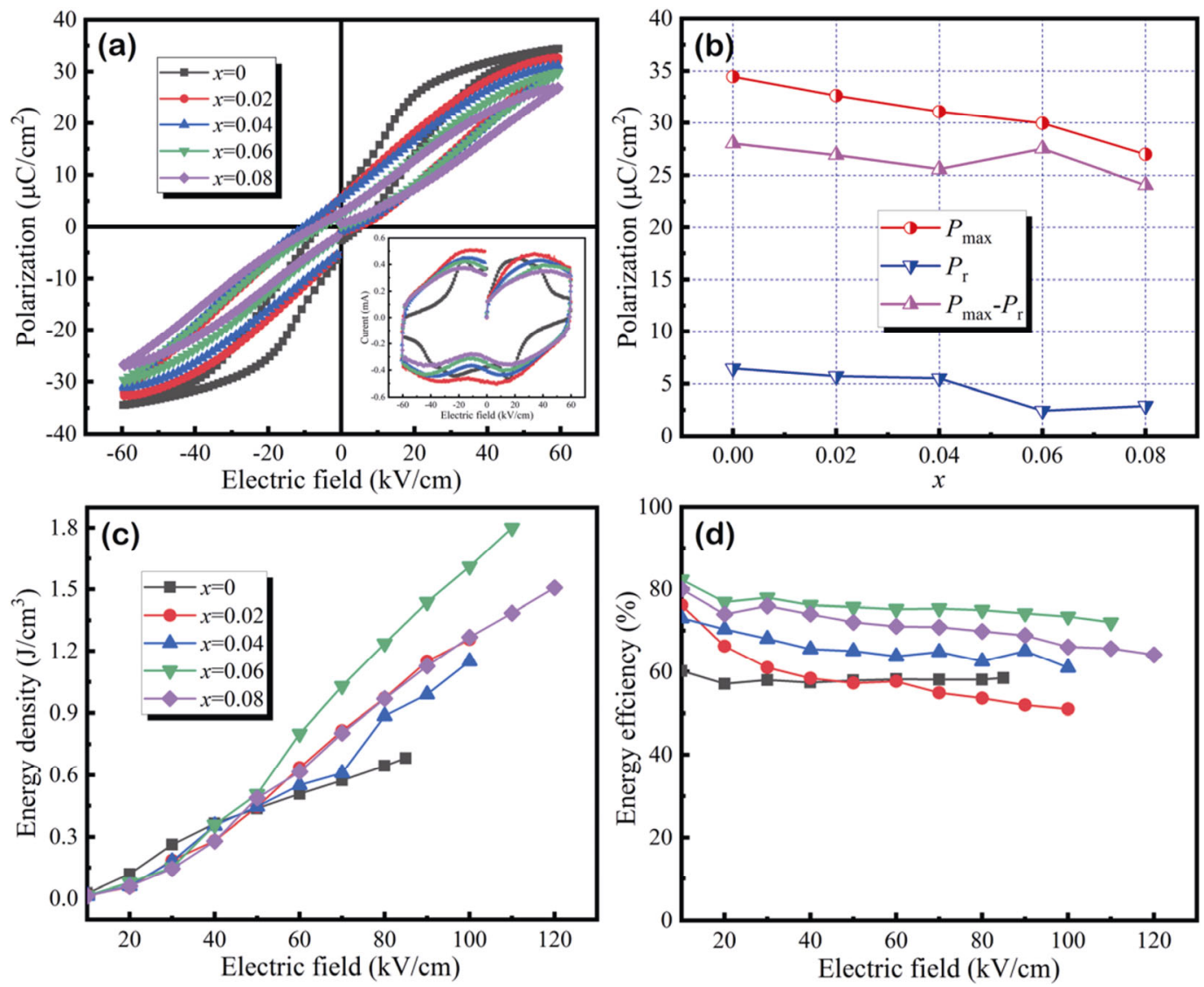

Fig. 6 (a) Measurement of $P-E$ loops at $60 \mathrm{kV} / \mathrm{cm}$ for $\mathrm{BNS}_{0.245-1.5 x} \square_{0.5 x} \mathrm{~B}_{0.325{ }_{x}} \mathrm{~T}$ ceramics with different $x$ values, and corresponding $I-E$ loops are shown in the inset; (b) $P_{\max }, P_{\mathrm{r}}$, and $P_{\max }-P_{\mathrm{r}}$ versus $x$ value for $\mathrm{BNS}_{0.245-1.5 x} \square_{0.5 x} \mathrm{~B}_{0.325+x} \mathrm{~T}$ ceramics at $60 \mathrm{kV} / \mathrm{cm}$; (c) recoverable energy density $W_{\text {rec }}$ and (d) energy efficiency $\eta$ as a function of applied electric field for $\mathrm{BNS}_{0.245-1.5 x} \square_{0.5 x} \mathrm{~B}_{0.325+x} \mathrm{~T}$ ceramics.

value increases, $P-E$ loops gradually go slim, which is beneficial for improving energy storage property, and the maximum polarization at a given electric field slightly decreases with the increase of $x$ value. Combined with $I-E$ loops at the same conditions, current peaks gradually diffuse, and corresponding intensity decreases, indicating the relaxor characteristic is enhanced [41]. In addition, $P_{\max }, P_{\mathrm{r}}$, and $P_{\max }-P_{\mathrm{r}}$ versus $x$ value for $\mathrm{BNS}_{0.245-1.5 x} \square_{0.5 x} \mathrm{~B}_{0.325+x} \mathrm{~T}$ ceramics at $60 \mathrm{kV} / \mathrm{cm}$ are exhibited in Fig. 6(b). A relatively high $P_{\max }-P_{\mathrm{r}}$ of $27.52 \mu \mathrm{C} / \mathrm{cm}^{2}$ can be obtained at $x=0.06$ composition due to a rapid decrease in $P_{\mathrm{r}}$, because the PNRs are dynamic sensitive to external electric field stimuli. Figures 6(c) and 6(d) show energy efficiency $\eta$ and recoverable energy density $W_{\text {rec }}$ of $\mathrm{BNS}_{0.245-1.5 x} \square_{0.5 x} \mathrm{~B}_{0.325+x} \mathrm{~T}$ ceramics at different electric fields, respectively. As $x$ value increases, $\eta$ presents an increased tendency obtaining a high value for $x=0.06$ composition, and then decreases again with further increasing $x$ value. Meanwhile, $\mathrm{BNS}_{0.245-1.5 x} \square_{0.5 x} \mathrm{~B}_{0.325+x} \mathrm{~T}$ ceramics with $x=$
0.06 possess a maximum $W_{\text {rec }}$ of $1.8 \mathrm{~J} / \mathrm{cm}^{3}$ only at a low electric field of $110 \mathrm{kV} / \mathrm{cm}$, as shown in Fig. 6(d).

In order to investigate the working stability at different external fields, temperature, frequency, and electric fatigue dependent energy storage properties of BNS $_{0.245-1.5 x} \square_{0.5 x} \mathrm{~B}_{0.325+x} \mathrm{~T}$ ceramics with $x=0.06$ have been examined. Figure 7(a) shows $P-E$ loops of $x=$ 0.06 ceramics over a temperature range of $30-150{ }^{\circ} \mathrm{C}$ at $60 \mathrm{kV} / \mathrm{cm}$ and $10 \mathrm{~Hz}$. As temperature increases, $P-E$ loops gradually go slim, and keep a high $P_{\mathrm{s}}$ and low $P_{\mathrm{r}}$. Therefore, $W_{\text {rec }}$ and $\eta$ of $x=0.06$ ceramics possess good temperature stability, as exhibited in Fig. 7(b). Meanwhile, frequency dependent $P-E$ loops of $x=$ 0.06 ceramics at $60 \mathrm{kV} / \mathrm{cm}$ are displayed in Fig. 7(c). It can be seen that energy loss has a slight increase tendency during discharge process, which may be related to vacancy defect pin domain wall. $W_{\text {rec }}$ and $\eta$ of $x=0.06$ ceramics, therefore, show a slight decrease at frequencies of $1-100 \mathrm{~Hz}$, as shown in Fig. 7(d). Finally, $P-E$ loops as a function of cycle number and 


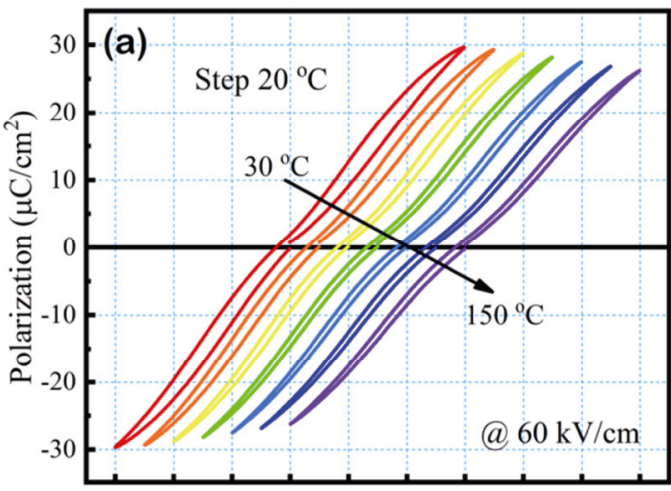

Electric field $(\mathrm{kV} / \mathrm{cm})$
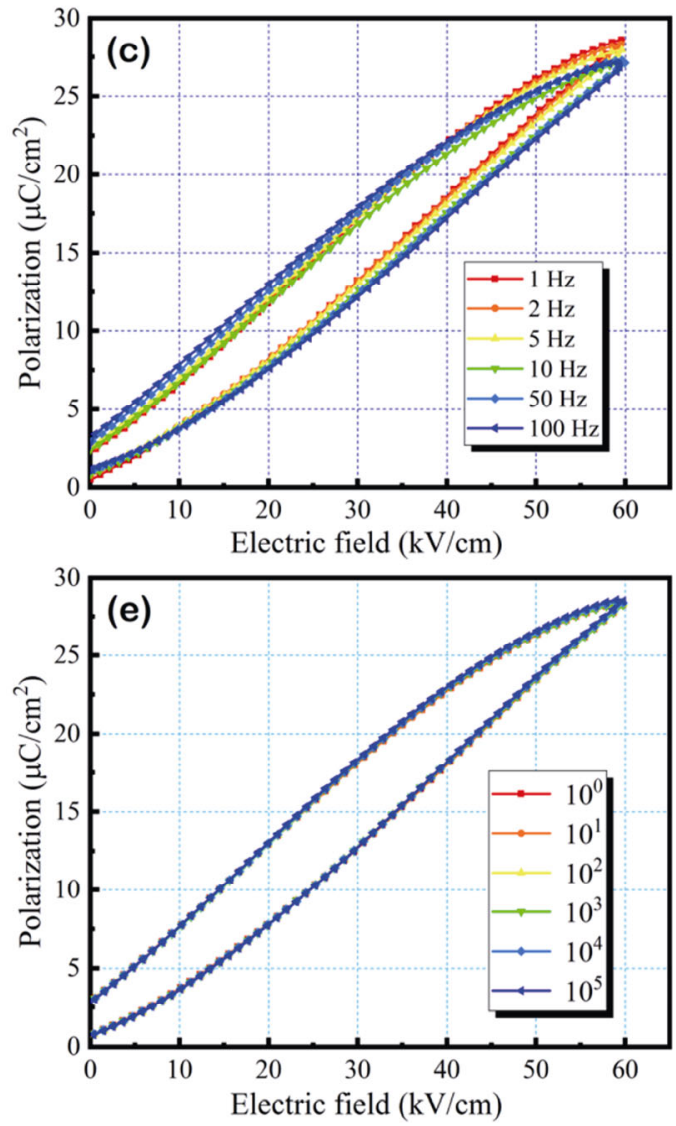
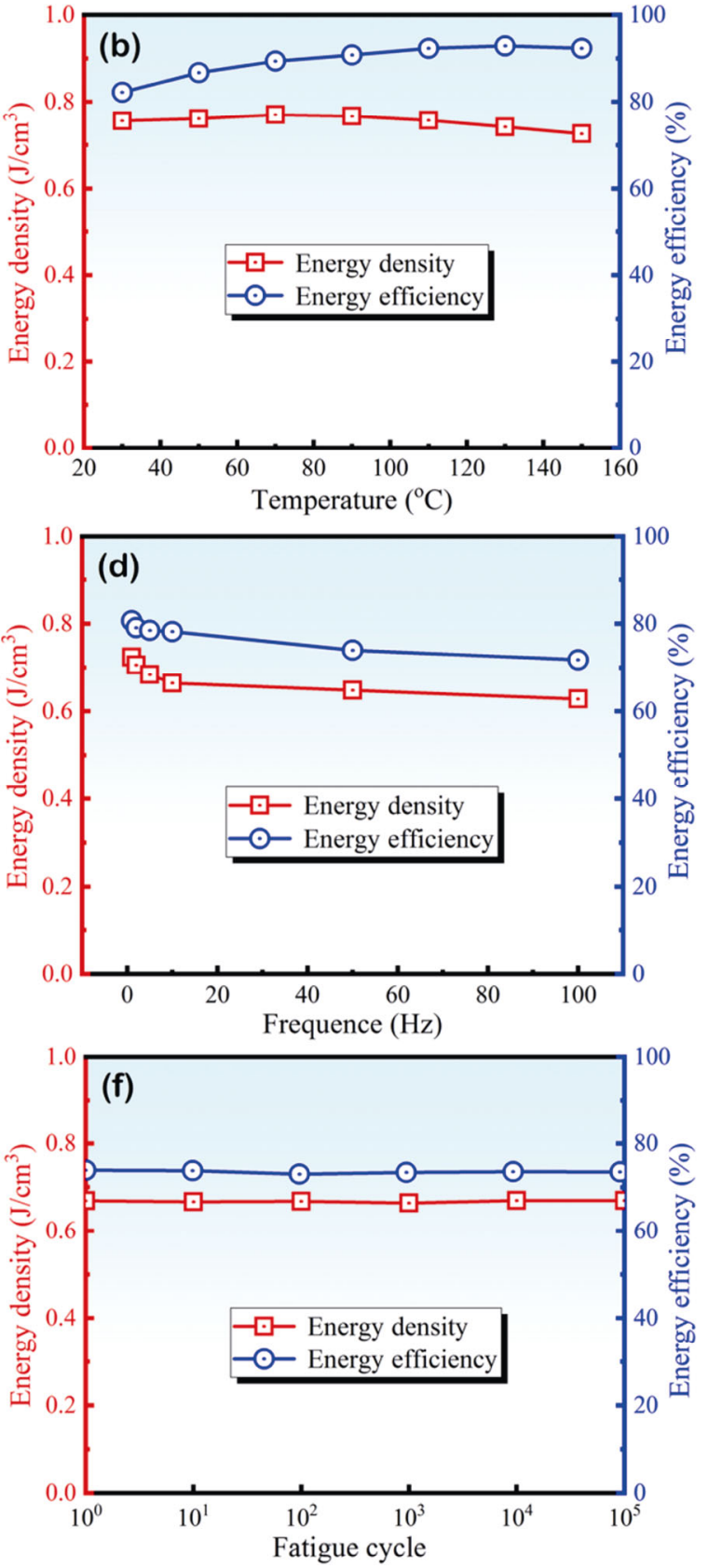

Fig. $7 P-E$ loops as a function of (a) temperature, (c) frequency, and (e) cycle number for $\mathrm{BNS}_{0.245-1.5 x} \square_{0.5 x} \mathrm{~B}_{0.325+x} \mathrm{~T}$ ceramics with $x=0.06$. $W_{\text {rec }}$ and $\eta$ as functions of (b) temperature, (d) frequency, and (f) cycle number for $\mathrm{BNS}_{0.245-1.5 x} \square_{0.5 x} \mathrm{~B}_{0.325+x} \mathrm{~T}$ ceramics with $x=0.06$.

corresponding $W_{\text {rec }}$ and $\eta$ for $x=0.06$ ceramics are illustrated in Figs. 7(e) and 7(f), respectively. Noted that polarization of $x=0.06$ ceramics keeps a stable value at $10 \mathrm{~Hz}$ after $10^{5}$ electric cycles. Obviously, $x=$ 0.06 ceramics possess a good fatigue endurance, and $W_{\text {rec }}$ and $\eta$ as functions of cycles are illustrated in Fig. 7(f).

Charge-discharge characteristic is an essential factor for dielectric materials to evaluate its energy storage capabilities, and thus charge-discharge measurement is fulfilled at a specified circuit. Generally, discharge energy density $W_{\mathrm{d}}$ can be calculated by the equation as Eq.(6) [42]:

$$
W_{\mathrm{d}}=\frac{R \int i^{2} \mathrm{~d} t}{V}
$$

where $R$ is the load resistance $(100 \Omega), i$ is the maximum discharge current, and $V$ is the effective volume of 

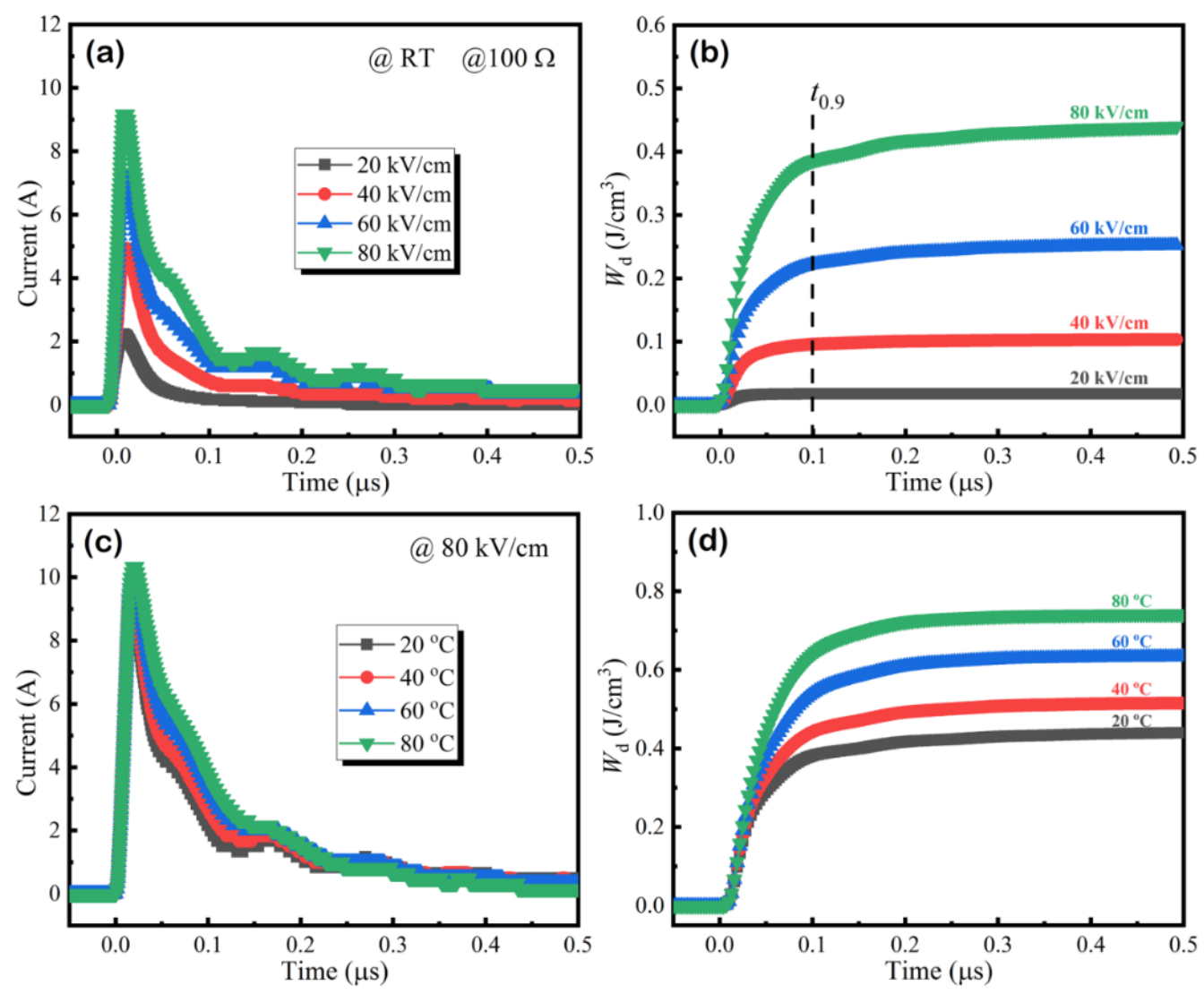

Fig. 8 (a) Overdamped discharge current curves and (b) corresponding discharge density $W_{\mathrm{d}}$ as a function of electric field for $x=0.06$ ceramics at room temperature, (c) overdamped discharge current curves, and (d) corresponding discharge density $W_{\mathrm{d}}$ as a function of temperature for $x=0.06$ ceramics at $80 \mathrm{kV} / \mathrm{cm}$.

ceramic between two electrodes. Figures 8(a) and 8(b) show room-temperature underdamped discharge waveform and corresponding $W_{\mathrm{d}}$ of $\mathrm{BNS}_{0.245-1.5 x} \square_{0.5 x} \mathrm{~B}_{0.325+x} \mathrm{~T}$ ceramics with $x=0.06$ ceramics at different electric fields. As the electric field increases, the maximum discharge current $I_{\max }$ and $W_{\mathrm{d}}$ both gradually enhance. It should be mentioned that $W_{\mathrm{d}}$ is less than $W_{\text {rec }}$ at the same electric field for $x=0.06$ composition. This may be attributed to the following two reasons [43]: One is that the domain cannot switch quickly to respond to the external electric field; and the other is that equivalent series resistance (ESR) generates Joule heat during charge-discharge process. The discharge rate is characterized by evaluating factor $t_{0.9}$ (the dashed line in Fig. 8(b)), which represents the time needed for releasing $90 \%$ of all stored energy [44]. Figure $8(\mathrm{~b})$ shows that $t_{0.9}$ is about $0.1 \mu \mathrm{s}$ for $x=0.06$ ceramics at room temperature, which illustrates that energy can be released by a pulse current way in a short time. Variable temperature discharge current curves as a function of time for $\mathrm{BNS}_{0.245-1.5 x} \square_{0.5 x} \mathrm{~B}_{0.325+x} \mathrm{~T}$ ceramics with $x=$ 0.06 ceramics are displayed in Fig. 8(c). As temperature increases, the maximum discharge current $I_{\max }$ basically keeps a stable value while $W_{\mathrm{d}}$ possesses an obvious enhancement as shown in Fig. 8(d). The discharge capability of $x=0.06$ ceramics possesses good temperature stability, which is beneficial for the application in high-temperature environment.

To better evaluate the energy storage properties of $\mathrm{BNS}_{0.245-1.5 x} \square_{0.5 x} \mathrm{~B}_{0.325+x} \mathrm{~T}$ ceramics, we compared $W_{\text {rec }}$ and $E_{\max }$ of $x=0.06$ and 0.08 compositions with some lead-free ceramic bulks reported previously [45-55]. It can be seen from Fig. 9(a) that a large $W_{\text {rec }}\left(>1.5 \mathrm{~J} / \mathrm{cm}^{3}\right)$ usually requires a high $E_{\mathrm{b}}(>160 \mathrm{kV} / \mathrm{cm})$ to produce high polarization, especially for some BT-based and $\mathrm{K}_{0.5} \mathrm{Na}_{0.5} \mathrm{NbO}_{3}$-based materials. In this work, a high $W_{\text {rec }}$ can be achieved under a relatively low electric field, which exceeds other BNT-based energy storage ceramics at the same electric field, even in other lead-free systems. With further comparing $W_{\text {rec }}$ and $\eta$ of different compositions, it could be noted that high $W_{\text {rec }}$ and $\eta$ are hard to obtain simultaneously in one system influenced by heat loss at electric field, as shown in Fig. 9(b). Noted that $\mathrm{BNS}_{0.1555} \square_{0.03} \mathrm{~B}_{0.385} \mathrm{~T}(x=0.06)$ 

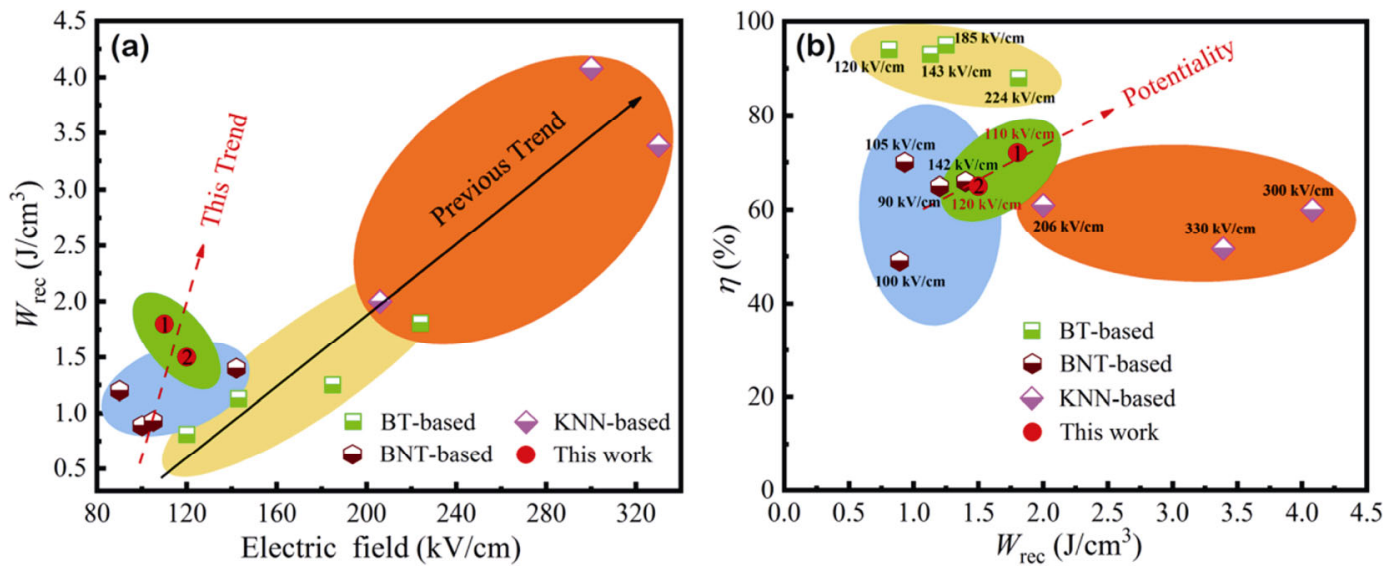

Fig. 9 A comparison of energy storage properties $\left(W_{\text {rec }}\right.$ and $\left.\eta\right)$ between some reported lead-free ferroelectric ceramics and this work. Note that 1 and 2 in the red ball denote the $x=0.06$ and $x=0.08$ compositions in this work, respectively.

ceramics possess a relatively high $W_{\text {rec }}\left(>1.5 \mathrm{~J} / \mathrm{cm}^{3}\right)$, together with a high $\eta(>70 \%)$ under relatively low electric field $(<160 \mathrm{kV} / \mathrm{cm})$, demonstrating that it is potential to obtain both high $W_{\text {rec }}$ and $\eta$, which should be a promising candidate for power ceramic capacitor application.

\section{Conclusions}

In this work, an A-site defect engineering is proposed to improve the energy storage performance of BNS $_{0.245-1.5 x} \square_{0.5 x} \mathrm{~B}_{0.325+x} \mathrm{~T}$ lead-free ceramics. High recoverable energy density of $1.8 \mathrm{~J} / \mathrm{cm}^{3}$ under low electric field (@110 kV/cm) and energy efficiency of $72 \%$ are achieved simultaneously in the sample with $x=0.06$. This good energy storage performance is attributed to the A-site defect engineering that can reduce $P_{\mathrm{r}}$. The ceramic also exhibits satisfactory temperature, frequency, and cycling stabilities as well as a high charge-discharge rate. $\mathrm{BNS}_{0.245-1.5 x} \square_{0.5 x} \mathrm{~B}_{0.325+x} \mathrm{~T}$ ( $x=$ $0.06)$ ceramics show a high dielectric constant of 2930 within $15 \%$ fluctuation in a wide temperature range of $40-350{ }^{\circ} \mathrm{C}$. This high-temperature stability is attributed to the A-site defect engineering, which can improve the thermal evolution of PNRs. All these advantages indicate that $\mathrm{BNS}_{0.245-1.5 x} \square 0.5 x \mathrm{~B}_{0.325+x} \mathrm{~T}$ ceramics are suitable for solid-state pulse power ceramic capacitors, and the A-site defect engineering is a robust strategy to improve the $W_{\text {rec }}$ and high-temperature stability of lead-free ceramics.

\section{Acknowledgements}

This work was financially supported by the National
Natural Science Foundation of China (No. 51767010) and the Key Project of Natural Science Foundation of Jiangxi Province of China (No. 20212ACB204010).

\section{References}

[1] Li DX, Zeng XJ, Li ZP, et al. Progress and perspectives in dielectric energy storage ceramics. $J$ Adv Ceram 2021, 10: 675-703.

[2] Sarjeant WJ, Clelland IW, Price RA. Capacitive components for power electronics. Proc IEEE 2001, 89: 846-855.

[3] Khanchaitit P, Han K, Gadinski MR, et al. Ferroelectric polymer networks with high energy density and improved discharged efficiency for dielectric energy storage. Nat Commun 2013, 4: 2845.

[4] Yao ZH, Song Z, Hao $\mathrm{H}$, et al. Homogeneous/ inhomogeneous-structured dielectrics and their energystorage performances. Adv Mater 2017, 29: 1601727.

[5] Palneedi H, Peddigari M, Hwang GT, et al. High-performance dielectric ceramic films for energy storage capacitors: Progress and outlook. Adv Funct Mater 2018, 28: 1803665.

[6] Pan H, Li F, Liu Y, et al. Ultrahigh-energy density lead-free dielectric films via polymorphic nanodomain design. Science 2019, 365: 578-582.

[7] Yan J, Wang Y, Wang CM, et al. Boosting energy storage performance of low-temperature sputtered $\mathrm{CaBi}_{2} \mathrm{Nb}_{2} \mathrm{O}_{9}$ thin film capacitors via rapid thermal annealing. $J A d v$ Ceram 2021, 10: 627-635.

[8] Peng BL, Tang SL, Lu L, et al. Low-temperature-poling awakened high dielectric breakdown strength and outstanding improvement of discharge energy density of $(\mathrm{Pb}, \mathrm{La})(\mathrm{Zr}, \mathrm{Sn}, \mathrm{Ti}) \mathrm{O}_{3}$ relaxor thin film. Nano Energy 2020, 77: 105132 .

[9] Dong GZ, Fan HQ, Liu LJ, et al. Large electrostrain in $\mathrm{Bi}_{1 / 2} \mathrm{Na}_{1 / 2} \mathrm{TiO}_{3}$-based relaxor ferroelectrics: A case study of $\mathrm{Bi}_{1 / 2} \mathrm{Na}_{1 / 2} \mathrm{TiO}_{3}-\mathrm{Bi}_{1 / 2} \mathrm{~K}_{1 / 2} \mathrm{TiO}_{3}-\mathrm{Bi}\left(\mathrm{Ni}_{2 / 3} \mathrm{Nb}_{1 / 3}\right) \mathrm{O}_{3}$ ceramics. $J$ 
Materiomics 2021, 7: 593-602.

[10] Rödel J, Jo W, Seifert KTP, et al. Perspective on the development of lead-free piezoceramics. J Am Ceram Soc 2009, 92: 1153-1177.

[11] Suchanicz J, Kluczewska-Chmielarz K, Sitko D, et al. Electrical transport in lead-free $\mathrm{Na}_{0.5} \mathrm{Bi}_{0.5} \mathrm{TiO}_{3}$ ceramics. $J$ Adv Ceram 2021, 10: 152-165.

[12] Li DX, Shen ZY, Li ZP, et al. $P-E$ hysteresis loop going slim in $\mathrm{Ba}_{0.3} \mathrm{Sr}_{0.7} \mathrm{TiO}_{3}$-modified $\mathrm{Bi}_{0.5} \mathrm{Na}_{0.5} \mathrm{TiO}_{3}$ ceramics for energy storage applications. $J$ Adv Ceram 2020, 9: 183-192.

[13] Zhao NS, Fan HQ, Ning L, et al. Temperature-stable dielectric and energy storage properties of $\mathrm{La}\left(\mathrm{Ti}_{0.5} \mathrm{Mg}_{0.5}\right) \mathrm{O}_{3}$-doped $\quad\left(\mathrm{Bi}_{0.5} \mathrm{Na}_{0.5}\right) \mathrm{TiO}_{3}-\left(\mathrm{Sr}_{0.7} \mathrm{Bi}_{0.2}\right) \mathrm{TiO}_{3}$ lead-free ceramics. $J$ Am Ceram Soc 2018, 101: 5578-5585.

[14] Sung YS, Kim JM, Cho JH, et al. Effects of Bi nonstoichiometry in $\left(\mathrm{Bi}_{0.5+x} \mathrm{Na}\right) \mathrm{TiO}_{3}$ ceramics. Appl Phys Lett 2011, 98: 012902.

[15] Gao F, Dong XL, Mao CL, et al. Energy-storage properties of $\quad 0.89 \mathrm{Bi}_{0.5} \mathrm{Na}_{0.5} \mathrm{TiO}_{3}-0.06 \mathrm{BaTiO}_{3}-0.05 \mathrm{~K}_{0.5} \mathrm{Na}_{0.5} \mathrm{NbO}_{3}$ lead-free anti-ferroelectric ceramics. J Am Ceram Soc 2011, 94: 4382-4386.

[16] Chen XL, Li X, Zhou HF, et al. Phase evolution, microstructure, electric properties of $\left(\mathrm{Ba}_{1-x} \mathrm{Bi}_{0.67 x} \mathrm{Na}_{0.33 x}\right)\left(\mathrm{Ti}_{1-x} \mathrm{Bi}_{0.33 x} \mathrm{Sn}_{0.67 x}\right) \mathrm{O}_{3}$ ceramics. $J A d v$ Ceram 2019, 8: 427-437.

[17] Lu XP, Xu JW, Yang L, et al. Energy storage properties of $\left(\mathrm{Bi}_{0.5} \mathrm{Na}_{0.5}\right)_{0.93} \mathrm{Ba}_{0.07} \mathrm{TiO}_{3}$ lead-free ceramics modified by $\mathrm{La}$ and Zr co-doping. J Materiomics 2016, 2: 87-93.

[18] Li JL, Li F, Xu Z, Zhang SJ. Multilayer lead-free ceramic capacitors with ultrahigh energy density and efficiency. Adv Mater 2018, 30: 1802155.

[19] Shen ZY, Wang Y, Tang YX, et al. Glass modified Barium strontium titanate ceramics for energy storage capacitor at elevated temperatures. J Materiomics 2019, 5: 641-648.

[20] Yan BB, Fan HQ, Yadav AK, et al. $\left[\left(\mathrm{Bi}_{0.50} \mathrm{Na}_{0.40} \mathrm{~K}_{0.10}\right)_{0.94} \mathrm{Ba}_{0.06}\right]_{1-x} \mathrm{La}_{x} \mathrm{Ti}_{0.975} \mathrm{Ta}_{0.025} \mathrm{O}_{3}$ lead-free relaxor ceramics with high energy storage density and thermally stable dielectric properties. J Mater Sci 2020, 55: 14728-14739.

[21] Ke SM, Fan HQ, Huang HT, et al. Dielectric dispersion behavior of $\mathrm{Ba}\left(\mathrm{Zr}_{x} \mathrm{Ti}_{1-x}\right) \mathrm{O}_{3}$ solid solutions with a quasiferroelectric state. $J$ Appl Phys 2008, 104: 034108.

[22] Liu ZY, Fan HQ, Lei SH, et al. Duplex structure in $\mathrm{K}_{0.5} \mathrm{Na}_{0.5} \mathrm{NbO}_{3}-\mathrm{SrZrO}_{3}$ ceramics with temperature-stable dielectric properties. J Eur Ceram Soc 2017, 37: 115-122.

[23] Cao WP, Li WL, Feng Y, et al. Defect dipole induced large recoverable strain and high energy-storage density in lead-free $\mathrm{Na}_{0.5} \mathrm{Bi}_{0.5} \mathrm{TiO}_{3}$-based systems. Appl Phys Lett 2016, 108: 202902.

[24] Xu YH, Liu XM, Wang GD, et al. Antiferroelectricity in tantalum doped $\left(\mathrm{Bi}_{0.5} \mathrm{Na}_{0.5}\right)_{0.94} \mathrm{Ba}_{0.06} \mathrm{TiO}_{3}$ lead-free ceramics. Ceram Int 2016, 42: 4313-4322.

[25] Li DX, Shen ZY, Li ZP, et al. Structural evolution, dielectric and ferroelectric properties of $(1-x) \mathrm{Bi}_{0.5} \mathrm{Na}_{0.5} \mathrm{TiO}_{3}-x \mathrm{Ba}_{0.3} \mathrm{Sr}_{0.7} \mathrm{TiO}_{3}$ ceramics. J Mater Sci: Mater Electron 2019, 30: 5917-5922.

[26] Li DX, Shen ZY, Li ZP, et al. Effect of $\left(\mathrm{Nb}_{2 / 3} \mathrm{Mg}_{1 / 3}\right)^{4+}$ complex on the dielectric and ferroelectric properties of $\left(\mathrm{Ba}_{0.3} \mathrm{Sr}_{0.7}\right)_{0.35}\left(\mathrm{Bi}_{0.5} \mathrm{Na}_{0.5}\right)_{0.65} \mathrm{TiO}_{3}$ ceramics for energy storage. J Mater Sci: Mater Electron 2020, 31: 3648-3653.

[27] Li Q, Wang C, Zhang WM, et al. Influence of compositional ratio $\mathrm{K} / \mathrm{Na}$ on structure and piezoelectric properties in $\left[\left(\mathrm{Na}_{1-x} \mathrm{~K}_{x}\right)_{0.5} \mathrm{Bi}_{0.5}\right] \mathrm{Ti}_{0.985} \mathrm{Ta}_{0.015} \mathrm{O}_{3}$ ceramics. $J$ Mater Sci 2019, 54: 4523-4531.

[28] Rout D, Moon KS, Kang SJL, et al. Dielectric and Raman scattering studies of phase transitions in the $(100-x) \mathrm{Na}_{0.5} \mathrm{Bi}_{0.5} \mathrm{TiO}_{3}-x \mathrm{SrTiO}_{3}$ system. $J$ Appl Phys 2010, 108: 084102 .

[29] McLaughlin K, Pascual-Gonzalez C, Wang DW, et al. Site occupancy and electric-field induced strain response of Er-doped $\left(\mathrm{Bi}_{0.4} \mathrm{Na}_{0.4} \mathrm{Sr}_{0.2}\right) \mathrm{TiO}_{3}$ ceramics. J Alloys Compd 2019, 779: 7-14.

[30] Tripathy SN, Mishra KK, Sen S, et al. Dielectric and Raman spectroscopic studies of $\mathrm{Na}_{0.5} \mathrm{Bi}_{0.5} \mathrm{TiO}_{3}-\mathrm{BaSnO}_{3}$ ferroelectric system. $J$ Am Ceram Soc 2014, 97: 1846-1854.

[31] Petzelt J, Kamba S, Fábry J, et al. Infrared, Raman and high-frequency dielectric spectroscopy and the phase transitions in $\mathrm{Na}_{1 / 2} \mathrm{Bi}_{1 / 2} \mathrm{TiO}_{3}$.J Phys: Condens Matter 2004, 16: $2719-2731$.

[32] Schütz D, Deluca M, Krauss W, et al. Lone-pair-induced covalency as the cause of temperature- and field-induced instabilities in bismuth sodium titanate. Adv Funct Mater 2012, 22: 2285-2294.

[33] Li F, Zhai JW, Shen B, et al. Influence of structural evolution on energy storage properties in $\mathrm{Bi}_{0.5} \mathrm{Na}_{0.5} \mathrm{TiO}_{3}-\mathrm{SrTiO}_{3}-\mathrm{NaNbO}_{3}$ lead-free ferroelectric ceramics. J Appl Phys 2017, 121: 054103.

[34] Xu Q, Ding SH, Song TX, et al. Effect of $\mathrm{Nd}_{2} \mathrm{O}_{3}$ doping on microstructure and dielectric properties of BCZT ceramics. J Chin Ceram Soc 2013, 41: 292-297. (in Chinese)

[35] Li DX, Shen ZY, Li ZP, et al. Optimization of polarization behavior in $(1-x)$ BSBNT $-x$ NN ceramics for pulsed power capacitors. J Mater Chem C 2020, 8: 7650-7657.

[36] Huang Y, Li F, Hao H, et al. $\left(\mathrm{Bi}_{0.51} \mathrm{Na}_{0.47}\right) \mathrm{TiO}_{3}$ based lead free ceramics with high energy density and efficiency. $J$ Materiomics 2019, 5: 385-393.

[37] Hu B, Fan HQ, Ning L, et al. Enhanced energy-storage performance and dielectric temperature stability of $(1-x)\left(0.65 \mathrm{Bi}_{0.5} \mathrm{Na}_{0.5} \mathrm{TiO}_{3}-0.35 \mathrm{Bi}_{0.1} \mathrm{Sr}_{0.85} \mathrm{TiO}_{3}\right)-x \mathrm{KNbO}_{3}$ ceramics. Ceram Int 2018, 44: 10968-10974.

[38] Dong GZ, Fan HQ, Jia YX, et al. Electro-mechano-optical properties of the $\mathrm{Er}^{3+}$ modified $\mathrm{Bi}_{0.5} \mathrm{Na}_{0.4} \mathrm{~K}_{0.1} \mathrm{TiO}_{3}$ versatile ceramics. J Eur Ceram Soc 2021, 41: 2488-2496.

[39] Xu CG, Lin DM, Kwok KW. Structure, electrical properties and depolarization temperature of $\left(\mathrm{Bi}_{0.5} \mathrm{Na}_{0.5}\right) \mathrm{TiO}_{3}-\mathrm{BaTiO}_{3}$ lead-free piezoelectric ceramics. Solid State Sci 2008, 10: 934-940. 
[40] Jo W, Schaab S, Sapper E, et al. On the phase identity and its thermal evolution of lead free $\left(\mathrm{Bi}_{1 / 2} \mathrm{Na}_{1 / 2}\right) \mathrm{TiO}_{3}-6 \mathrm{~mol} \%$ $\mathrm{BaTiO}_{3}$. J Appl Phys 2011, 110: 074106.

[41] Xu Q, Li TM, Hao H, et al. Enhanced energy storage properties of $\mathrm{NaNbO}_{3}$ modified $\mathrm{Bi}_{0.5} \mathrm{Na}_{0.5} \mathrm{TiO}_{3}$ based ceramics. J Eur Ceram Soc 2015, 35: 545-553.

[42] Tian J, Wang SJ, Jiang T, et al. Dielectric characterization of a novel $\mathrm{Bi}_{2} \mathrm{O}_{3}-\mathrm{Nb}_{2} \mathrm{O}_{5}-\mathrm{SiO}_{2}-\mathrm{Al}_{2} \mathrm{O}_{3}$ glass-ceramic with excellent charge-discharge properties. J Eur Ceram Soc 2019, 39: 1164-1169.

[43] Yang LT, Kong X, Li F, et al. Perovskite lead-free dielectrics for energy storage applications. Prog Mater Sci 2019, 102: 72-108.

[44] Ahn CW, Amarsanaa G, Won SS, et al. Antiferroelectric thin-film capacitors with high energy-storage densities, low energy losses, and fast discharge times. ACS Appl Mater Interfaces 2015, 7: 26381-26386.

[45] Hu QY, Jin L, Wang T, et al. Dielectric and temperature stable energy storage properties of $0.88 \mathrm{BaTiO}_{3}-0.12 \mathrm{Bi}\left(\mathrm{Mg}_{1 / 2} \mathrm{Ti}_{1 / 2}\right) \mathrm{O}_{3}$ bulk ceramics. $J$ Alloys Compd 2015, 640: 416-420.

[46] Benyoussef M, Zannen M, Belhadi J, et al. Dielectric, ferroelectric, and energy storage properties in dysprosium doped sodium bismuth titanate ceramics. Ceram Int 2018, 44: 19451-19460.

[47] Wei M, Zhang JH, Wu KT, et al. Effect of $\mathrm{BiMO}_{3}(\mathrm{M}=\mathrm{Al}$, In, Y, Sm, Nd, and $\mathrm{La}$ ) doping on the dielectric properties of $\mathrm{BaTiO}_{3}$ ceramics. Ceram Int 2017, 43: 9593-9599.

[48] Wang BY, Luo LH, Jiang XJ, et al. Energy-storage properties of $(1-x) \mathrm{Bi}_{0.47} \mathrm{Na}_{0.47} \mathrm{Ba}_{0.06} \mathrm{TiO}_{3}-x \mathrm{KNbO}_{3}$ lead-free ceramics. J Alloys Compd 2014, 585: 14-18.

[49] Zhang M, Yang HB, Li D, et al. Excellent energy density and power density achieved in $\mathrm{K}_{0.5} \mathrm{Na}_{0.5} \mathrm{NbO}_{3}$-based ceramics with high optical transparency. J Alloys Compd 2020, 829: 154565.

[50] Yang ZT, Gao F, Du HL, et al. Grain size engineered lead-free ceramics with both large energy storage density and ultrahigh mechanical properties. Nano Energy 2019, 58: 768-777.

[51] Zhao XB, Zhou ZY, Liang RH, et al. High-energy storage performance in lead-free $(1-x) \mathrm{BaTiO}_{3}-x \mathrm{Bi}\left(\mathrm{Zn}_{0.5} \mathrm{Ti}_{0.5}\right) \mathrm{O}_{3}$ relaxor ceramics for temperature stability applications. Ceram Int 2017, 43: 9060-9066.

[52] Wu LW, Wang $\mathrm{XH}$, Li LT. Lead-free $\mathrm{BaTiO}_{3}-\mathrm{Bi}\left(\mathrm{Zn}_{2 / 3} \mathrm{Nb}_{1 / 3}\right) \mathrm{O}_{3}$ weakly coupled relaxor ferroelectric materials for energy storage. $R S C A d v 2016,6$ : 14273-14282.

[53] Shao TQ, Du HL, Ma H, et al. Potassium-sodium niobate based lead-free ceramics: Novel electrical energy storage materials. J Mater Chem A 2017, 5: 554-563.

[54] Wang $\mathrm{T}$, Jin L, Li CC, et al. Relaxor ferroelectric $\mathrm{BaTiO}_{3}-\mathrm{Bi}\left(\mathrm{Mg}_{2 / 3} \mathrm{Nb}_{1 / 3}\right) \mathrm{O}_{3}$ ceramics for energy storage application. J Am Ceram Soc 2015, 98: 559-566.

[55] Qi H, Zuo RZ. Linear-like lead-free relaxor antiferroelectric $\left(\mathrm{Bi}_{0.5} \mathrm{Na}_{0.5}\right) \mathrm{TiO}_{3}-\mathrm{NaNbO}_{3}$ with giant energy-storage density/efficiency and super stability against temperature and frequency. J Mater Chem A 2019, 7: 3971-3978.

Open Access This article is licensed under a Creative Commons Attribution 4.0 International License, which permits use, sharing, adaptation, distribution and reproduction in any medium or format, as long as you give appropriate credit to the original author(s) and the source, provide a link to the Creative Commons licence, and indicate if changes were made.

The images or other third party material in this article are included in the article's Creative Commons licence, unless indicated otherwise in a credit line to the material. If material is not included in the article's Creative Commons licence and your intended use is not permitted by statutory regulation or exceeds the permitted use, you will need to obtain permission directly from the copyright holder.

To view a copy of this licence, visit http://creativecommons. org/licenses/by/4.0/. 